\title{
Fatal Septic Shock Associated with Herpes Simplex Virus Hepatitis: A Case Report
}

\author{
$\underline{\text { Valentine Inthasot }}^{1 \S}$, Adonis Goushchi ${ }^{1 \S}$, Silvia Lazzaroni ${ }^{1}$, Alberto Papaleo ${ }^{1}$, Maria Gomez Galdon², Didier Chochrad ${ }^{3}$ \\ ${ }^{1}$ Internal Medicine Department, Iris South Hospitals, Brussels, Belgium \\ ${ }^{2}$ Anatomical Pathology Department Institut Jules Bordet, Brussels, Belgium \\ ${ }^{3}$ Intensive Care Unit, Iris South Hospitals, Brussels, Belgium
}

Received: 03/11/2018

Accepted: 09/11/2018

Published: $27 / 11 / 2018$

How to cite this article: Inthasot V, Goushchi A, Lazzaroni S, Papaleo A, Gomez Galdon M, Chochrad D. Fatal septic shock associated with herpes simplex virus hepatitis: a case report. EJCRIM 2018;5: doi:10.12890/2018_000982.

${ }^{\S}$ Both authors contributed equally to this work.

Conflicts of Interests: The Authors declare that there are no competing interests.

This article is licensed under a Commons Attribution Non-Commercial 4.0 License

\section{ABSTRACT}

Herpes simplex viruses are endemic worldwide, with an estimated seroprevalence of approximately $70 \%$ in developed countries. However, it is less well known that they are one of the viral causes of fulminant hepatitis $(<2 \%)$ and constitute $<1 \%$ of all causes of acute liver failure. We describe the case of an 89-year-old man who developed sepsis caused by a urinary tract infection due to drug-sensitive Escherichia coli. After empirical treatment with piperacillin-tazobactam was initiated, the patient's condition worsened with shock, acute liver and renal failure, encephalopathy and persistent fever, that led to admission to the intensive care unit. The emergence of an acute abdomen prompted exploratory laparotomy but the patient died soon after surgery from abdominal haemorrhage. Immunohistochemical analysis of a liver biopsy specimen identified herpes simplex virus (HSV) hepatitis. The authors emphasize the need for better understanding of this rare condition in order to more precisely identify patients at risk who need more aggressive evaluation and empirical treatment, especially patients presenting with marked hepatic cytolysis with a rapidly worsening clinical evolution.

\section{LEARNING POINTS}

- Herpes simplex virus hepatitis should be considered in patients with acute liver failure.

- This condition can occur even in immunocompetent individuals.

- Empirical treatment with aciclovir should be initiated in case of clinical suspicion.

\section{KEYWORDS}

Acute liver failure, hepatitis, herpes simplex virus, septic shock

\section{CASE DESCRIPTION}

An 89-year-old man was admitted to the emergency room after a fall. His medical history included hypertension, hypercholesterolaemia, mild chronic kidney disease and a suspicion of frontotemporal dementia with a vascular component. He lived alone with help from a property manager due to his cognitive disorders. He had undergone several orthopaedic procedures including osteosynthesis for a fracture of the right tibia after a car accident, a hip replacement for coxarthrosis, and osteosynthesis of a left humeral fracture after a fall 3 months previously. He had last stayed in hospital 1 week earlier when he had been treated with amoxicillin-clavulanic acid for bronchitis. He only took aspirin and a proton pump inhibitor as daily medication at home. No alcohol use or smoking was noted. On admission, the patient complained of parietal left thoracic pain. His vital signs were normal. The physical examination was unremarkable except for a graze in the left thoracic area which the patient had sustained in a fall. 
During his stay, the patient presented fever with mild blood inflammatory markers (white blood cells 5,920/mm with a high neutrophil count and a C-reactive protein which remained at 22-81 mg/l during his entire hospital stay) without any other clinical signs. However, his clinical condition deteriorated with severe hypotension. Empirical antibiotic treatment with piperacillin-tazobactam was initiated to combat infection. The bacteriological investigation showed the presence of drug-sensitive Escherichia coli in the blood culture and the urine. Despite treatment, the patient's status worsened with fever and haemodynamic instability. Laboratory studies showed early signs of multiple organ failure with high liver enzymes (with AST increasing from $138 \mathrm{IU} / \mathrm{I}$ to 7,109 IU/I and ALT increasing from $103 \mathrm{IU} / \mathrm{I}$ to 2,108 IU/I during his stay in the emergency department and intensive care unit) without cholestasis or hyperbilirubinemia, coagulopathy, acute kidney injury, thrombopenia, leucopenia (white blood cells 3,200/mm3) and lymphopenia (lowest value 160/(mm ${ }^{3}$ ). The patient was transferred to the intensive care unit for the management of shock, and haemodialysis for acute renal failure with metabolic acidosis and encephalopathy was initiated.

An aetiological investigation was conducted to look for another infection with a hepatotropic virus, a disseminated intravascular coagulopathy or a haemophagocytic lymphohistiocytosis. The thoraco-abdominal contrast-enhanced computed tomography examination was normal. The results of serological tests for parvovirus B19, CMV, EBV, hepatitis A, B, C, D, E and HIV showed no current infection. No antinuclear antibodies or anti-neutrophil cytoplasmic antibodies were found. Other laboratory tests revealed hyperferritinaemia ( $>10,000$ $\mu \mathrm{g} / \mathrm{l})$, hypertriglyceridaemia (308 mg/dl), high D-dimer levels (>10,000 ng/ml) and high serum lactate dehydrogenase. Plasma fibrinogen was low (86 mg/dl). The factor VIII plasma concentration was within normal range (83\%). Two days after admission to the intensive care unit, the patient deteriorated with an acute abdomen and acute anaemia which prompted an exploratory emergency laparotomy. During the procedure, the liver surface was seen to be covered with numerous white 'rice' spots and a biopsy was taken. No active bleeding was seen. The patient died soon after surgery from abdominal haemorrhage. Immunohistochemical analysis identified the infection as herpes simplex virus (HSV) hepatitis (Figs. 1-4).

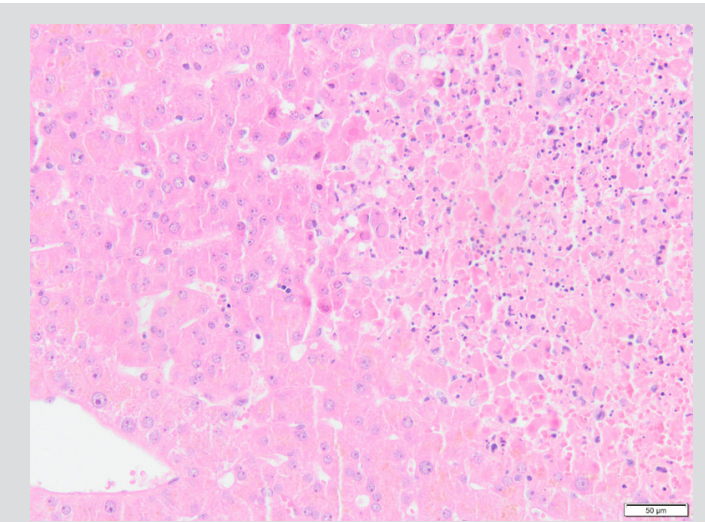

Figure 1. Right: submassive coagulative necrosis involving centrilobular zone 3. The necrotic zone is surrounded by hepatocytes with typical viral inclusions. There is minimal inflammation around the necrosis. Left: the centrolobular vein is spared

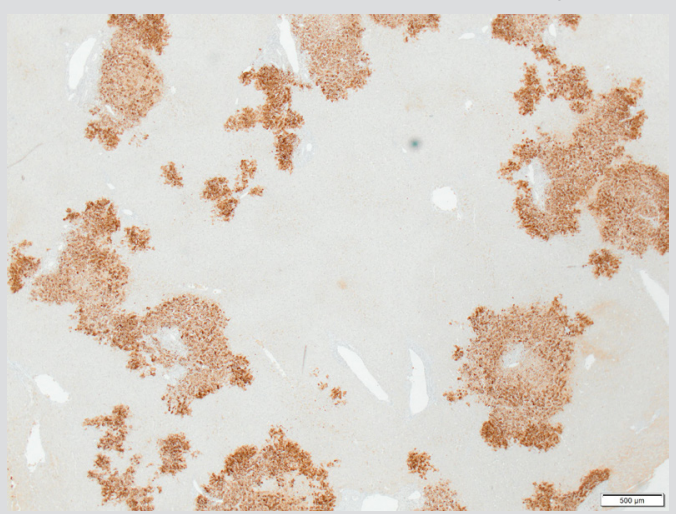

Figure 3. Immunostaining for herpes simplex shows infected cells in randomly distributed areas of coagulative necrosis

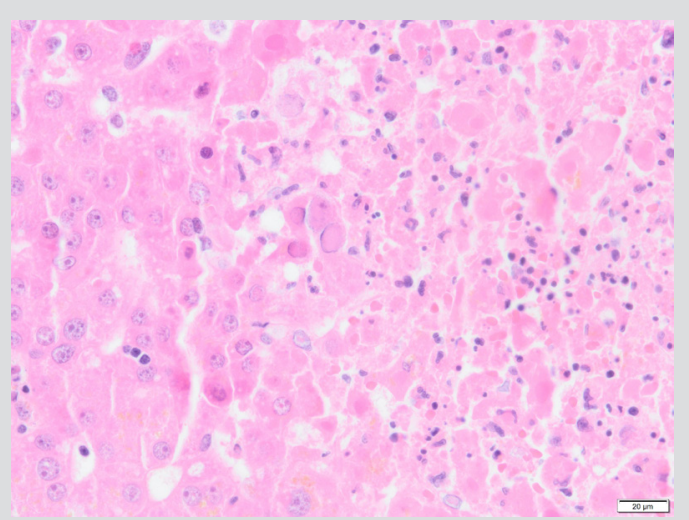

Figure 2. Viral nuclear inclusions

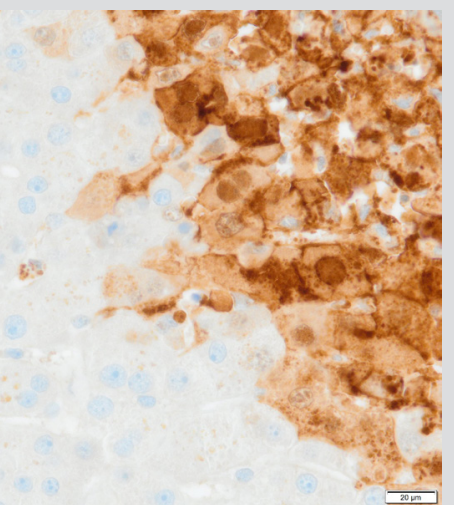

Figure 4. Immunostaining for herpes simplex (high magnification) 


\section{DISCUSSION}

Herpes simplex viruses are endemic worldwide, with an estimated seroprevalence of approximately $70 \%$ in developed countries ${ }^{[1]}$. However, it is less well known that they are one of the viral causes of fulminant hepatitis $(<2 \%)$ and constitute $<1 \%$ of all causes of acute liver failure ${ }^{[2]}$. HSV hepatitis has been mainly described in immunocompromised patients and pregnant women in the late second and third trimesters ${ }^{[3]}$, but also in immunocompetent hosts ${ }^{[4]}$. The clinical-biological presentation is not specific, but the triad of fever, markedly elevated liver enzymes and leucopenia can suggest this condition ${ }^{[5]}$.

The difficulty in diagnosing HSV hepatitis leads to frequent post-mortem diagnoses $(57.6 \%)^{[4]}$. In our case, the differential diagnosis remained a challenge, especially as urosepsis caused by E. coli was also present and the patient was not immunocompromised. The parsimony principle suggests that the evolution was secondary to this infection rather than a co-infection.

Ante-mortem diagnostic tools include the detection and quantification ${ }^{[6]}$ of blood viral HSV DNA, liver biopsy and serological testing for $\mathrm{HSV}^{[7]}$. In rare cases, some lesions can be seen on computed tomography imaging ${ }^{[8]}$. Treatment includes aciclovir, which is effective in $51 \%$ of $\operatorname{cases}^{[4]}$. Timing may be decisive ${ }^{[9]}$. The unfortunate outcome in our patient thus may have been be related to delays in diagnosis and treatment, despite the identification of some variables associated with death ${ }^{[4]}$. HSV hepatitis may mimic septic shock or hepatic failure itself ${ }^{[3]}$; our patient did indeed have septic shock complicated by a disseminated intravascular coagulopathy and a possible haemophagocytic lymphohistiocytosis.

In conclusion, there is a need for better understanding of this rare disease in order to more precisely identify patients at risk who need more aggressive evaluation and empirical treatment, especially patients presenting with marked hepatic cytolysis with a rapidly worsening clinical evolution.

\section{REFERENCES}

1. Roizman B, Knipe DM, Whitley RJ. Herpes simplex virus. In: Knipe DM, Howley PM, editors. Fields virology, 5th edn. Baltimore: Lippincott Williams \& Wilkins; 2007, pp. 2502-2557.

2. Schiødt FV, Davern TJ, Shakil AO, McGuire B, Samuel G, Lee WM. Viral hepatitis-related acute liver failure. Am J Gastroenterol 2003;98:448-453.

3. Kaufman B, Gandhi SA, Louie E, Rizzi R, Illei P. Herpes simplex virus hepatitis: case report and review. Clin Infect Dis 1997;24:334-338.

4. Norvell JP, Blei AT, Jovanovic BD, Levitsky J. Herpes simplex virus hepatitis: an analysis of the published literature and institutional cases. Liver Transpl 2007;13:1428-1434.

5. Ichai P, Roque Afonso AM, Sebagh M, Gonzalez ME, Codés L, Azoulay D, et al. Herpes simplex virus-associated acute liver failure: a difficult diagnosis with a poor prognosis. Liver Transpl 2005;11:1550-1555.

6. Beersma MF, Verjans GM, Metselaar HJ, Osterhaus AD, Berrington WR, van Doornum GJ. Quantification of viral DNA and liver enzymes in plasma improves early diagnosis and management of herpes simplex virus hepatitis. J Viral Hepat 2011;18:e160-e166.

7. Levitsky J, Duddempudi AT, Lakeman FD, Whitley RJ, Luby JP, Lee WM, et al. Detection and diagnosis of herpes simplex virus infection in adults with acute liver failure. Liver Transpl 2008;14:1498-1504.

8. Tripuraneni V, Patel K, Brennan TV, Ho LM. Fulminant herpes simplex viral hepatitis: ultrasound and CT imaging appearance and a review of the imaging literature. Clin Imaging 2014;38:191-194.

9. Navaneethan U, Lancaster E, Venkatesh PG, Wang J, Neff GW. Herpes simplex virus hepatitis - it's high time we consider empiric treatment. J Gastrointestin Liver Dis 2011;20:93-96. 
European Journal

of Case Reports in

Internal Medicine 